\title{
As Consequências dos Conteúdos Universalistas e os Princípios Republicanos Numa Sociedade Pluralista
}

\author{
The Consequences of Universalist Contents and the Republican \\ Principles in a Pluralist Society.
}

José Aguiar Nobre

(Pontifícia Universidade Católica de São Paulo, Brasil)

\begin{abstract}
Resumo
Os contrastes multiculturais se agudizam. Isso gera conflitos diante de uma cultura na qual os estados nacionais, se reúnem em unidades supranacionais. Sabe-se que essa reunião acontece sem que os cidadãos de determinada comunidade mundial sejam consultados. De modo que eles são inseridos a contragosto e involuntariamente numa comunidade de risco. Frente a isso, indaga-se: como possibilitar que o respeito por todos e a responsabilidade solidária para cada um sejam garantidos? Do ponto de vista metodológico, trata-se de uma pesquisa bibliográfica que versará sobre as questões inerentes ao direito interna-cional a partir da filosofia desenvolvida na obra de Jürgen Habermas. A pesquisa objetiva tecer reflexões no sentido de discutir acerca das questões inerentes tanto à soberania nacional quanto à importância e ou os limites dos blocos regionais na seara do direito interna-cional. Os resultados circunscrevem a compreensão de que a estrutura relacional da diferença diante de uma moral do respeito mútuo e da solidariedade recíproca deverá ser mantida, independentemente de qualquer coisa, em face da interposição de uma cultura global.
\end{abstract}

Palavra-chave: Conteúdo universalista. Jürgen Habermas. Direito internacional. Respeito. Solidariedade.

\begin{abstract}
Multicultural contrasts sharpen in contemporaneity. This generates numerous conflicts before a culture in which national states meet in supranational units. It is known that this meeting happens without the citizens of a given world community being consulted. So they are unwillingly and involuntarily inserted into a community at risk. In the face of this, we ask ourselves: How can we ensure that respect for all and the responsibility of solidarity for each one are guaranteed? From the methodlogical point of view, this is a bibliographical research that will deal with the inherent issues of international law from the philosophy developed in the work of Jürgen Habermas. The research aims at reflecting on the issues inherent in both national sovereignty and the importance and / or limits of regional blocs in the area of international law. The expected results are limited to the understanding that the relational structure of difference in the face of a morality of mutual respect and reciprocal solidarity must be maintained, independently of anything, in the face of the interposition of a global culture.
\end{abstract}

Keywords: Universalist contente. Jürgen Habermas. International right. Respect. Solidarity. 


\section{Introdução}

À luz da clássica deontologia kantiana, de que se deve fazer o bem não por inclinação sensível, mas por puro dever, e partindo das estruturas hoje existentes na seara da política internacional, a presente investigação se propõe a pensar uma constituição política da sociedade mundial descentralizada, ou seja, isso se efetiva como um sistema de múltiplos níveis em que, por boas razões, não poderá faltar o respectivo caráter estatal como um todo. $\mathrm{O}$ presente texto tem a desafiadora tarefa de pensar a política internacional, no plano nacional ou transnacional, sobre a organização de política mundial em face dos seus desafios de reformas no tempo presente, sem negligenciar as dimensões nacionais e regionais da política em prol dos direitos humanos, ambientais e da constituição da paz e banimento das guerras. Neste sentido, entre introdução e considerações finais, o texto está dividido com os seguintes itens: (i) um universalismo dotado de sensibilidade para as diferenças e a inclusão; (ii) As tensões em níveis locais, regionais e nacionais e a filosofia do direito de Habermas; (iii) $\mathrm{O}$ ocidente dividido e os entraves de uma cultura da polarização. Neste sentido é que se pretende convidar o leitor para uma oportunidade de pensar os desafios inerentes à política e ao direito internacional onde se põe, muitas vezes, um conteúdo de forma universal sem levar em consideração que ele se choca com as particularidades dos princípios republicanos, em face das mais diversas particularidades culturais, constituídas de suas riquezas regionais e desafios de as manter e conservar para que o esfacelamento identitário não se efetive. Eis o texto.

122 • Ágora Filosófica, Recife, v. 21, n. 1, p. 121-144, jan./abr., 2021 


\section{Um Universalismo Dotado de Sensibilidade para as Diferenças e a Inclusão}

Argumenta-se que o processo de educação para a existência coletiva, que seja solidária e ao mesmo tempo que saiba valorizar as riquezas das culturas individuais, promovendo a cultura do encontro e convivialidade sem que cada um perca a sua identidade, reivindica uma convivência necessariamente talhada pela alteridade. Nesse sentido, se faz mister entender que, "a responsabilidade solidária para com um outro como um de nós se refere ao "nós" flexível de uma comunidade que se opõe a tudo o que é substancial e que amplia constantemente seus limites porosos" (HABERMAS, 2002, p. 28). Entende-se que a ampliação das fronteiras de modo que elas se tornem porosas como acima referidas, efetiva-se essencialmente na medida em que seja possível a abolição da discriminação e do sofrimento, cuja inclusão dos marginalizados em geral, e de cada marginalizado em particular, se torne uma realidade. Argumenta-se que, a simples referência à porosidade das diferentes culturas evidencia a sua riqueza inerente de abertura e crescimento ao outro. Quando se tem em mente a importância da porosidade inerente às culturas, num mundo que, paradoxalmente, se torna uma aldeia global, mas com característica impermeáveis, é desafiado a captar a importância de se promover o encontro das diversas realidades culturais, tais como elas são em suas origens: porosas, isto é que estão abertas a acolher as riquezas do novo e oferecer também as suas riquezas, sem que as suas identidades estejam em riscos. Entender esta perspectiva na contemporaneidade torna-se um desafio a ser enfrentado e assimilado.

Em face da lógica global de protecionismos políticos

Ágora Filosófica, Recife, v. 21, n. 1, p. 121-144, jan./abr., 2021 • 123 
e impermeabilidades xenofóbicas das fronteiras contemporâneas de alguns países, esta reflexão deseja oferecer a sua contribuição e espera ter alguma relevância. Contribuição no sentido de convidar o leitor para olhar nesta direção de valorização e respeito pela cultura, e do modo de viver do outro, como uma riqueza que, pelo simples fato de existir, já constitui em si uma grandeza que deverá ser vista, respeitada, conservada e valorizada. Sabe-se que a extinção de qualquer cultura constituirá na mutilação do próprio planeta e, indubitavelmente, mesmo que não seja vista a olho nu por todos, aos que a elas conheciam, a cicatriz se torna visível e imperdoável. Em outras palavras, esta é uma forma de pensar que deverá ser acrescida por um magis, um plus, no sentido de uma advertência para a inalienável valorização recíproca de cada um.

A partir desta compreensão, ao contrário do que se possa parecer, entende-se que a filosofia do direito de Jürgen Habermas possibilita o entendimento de que são "as impressionantes conquistas do Estado nacional democrático e de seus princípios constitucionais republicanos que podem nos ensinar como deveríamos lidar com os problemas atuais da inevitável passagem para as formas de socialização pós-nacionais" (HABERMAS, 2018, p. 29). É nesse sentido, que se faz necessário "derrubar os muros da ignorância e da intransigência" como advertiu a chanceler alemã, Ângela Merkel, no dia 30 de maio de 2019, em uma cerimônia de formatura na Universidade de Harvard, contra todo tipo de política protecionista e isolacionista. Na fala da Merkel, tais políticas não levam em conta o outro que, inevitavelmente merecedor de inclusão e de respeito. A esse respeito ela ponderou que:

124 • Ágora Filosófica, Recife, v. 21, n. 1, p. 121-144, jan./abr., 2021 
Mais do que nunca, nosso modo de pensar e nossas ações devem ser multilaterais, e não unilaterais; globais e não nacionais; voltadas para o exterior, em vez de calcadas no isolacionismo, (...). Nossas liberdades individuais não são dadas. A democracia não é algo que podemos considerar garantida. Nem a paz ou a prosperidade. (MERKEL, 2019, FI SP, A2).

Quando não se perde de vista que as liberdades individuais não são dadas, mas alcançadas por meio de grande esforço de respeitos mútuos, e tento também plena consciência de que a democracia, a paz e prosperidades não são algo que se devem considerar garantidas para sempre, se faz necessário defender, respeitar, manter e conservar como uma forma de garantir também a vocação humana de viver a sua humanidade genuína, cuja conservação, não somente da espécie humana, é uma questão de instinto vital, como também de conservação do cosmo. Nesse sentido, em se tratando de uma questão, como por exemplo, o cuidado com a casa comum, como os acordos de combate à poluição e o zelo para com a camada de ozônio, por exemplo, não se pode prescindir de acordos de legitimidade transnacionais a fim de que a vida de qualidade indistintamente para todos, seja buscada, defendida e respeitada, com o intuito de que ela seja possível hoje e no futuro para todos. Como a solidariedade e a própria condição de partilhar do destino comum a que a humanidade está sujeita, como o próprio surto sanitário do Covid-19 deixa transparecer, ao tomar decisões em nível internacional, se faz necessário pensar na coletividade e não apenas em quem pode tomar decisões com favorecimento próprio, em detrimento da 
comunidade internacional. Neste ponto, está implícito, de forma evidente, um chamamento para a responsabilidade ética que em ninguém deverá ficar de fora. Desse modo, o direito global/supranacional que propugna a defesa dos direitos humanos e a busca da paz mundial, reivindica uma postura coletiva por parte de todos os países a fim de que tantos as questões ambientais, fiscais, econômicas e de solidariedade ${ }^{1}$ sejam respeitadas.

Ao tratar desse ponto, se faz necessário entender ainda, que "a inclusão não significa aqui confinamento dentro do próprio e fechamento diante do alheio. Antes, a 'inclusão do outro' quer dizer que as fronteiras da comunidade estão abertas a todos - e especialmente para aqueles que são estranhos uns aos outros e que querem permanecer estranhos" (HABERMAS, 2018, p. 28). Neste modo de entender, é que a filosofia do cosmopolitismo habermasiano aponta para a necessidade do cultivo de uma noção de justiça política e cidadã em que o outro tem o direito de querer permanecer estranho, ou seja, que não se sentirá jamais no dever de modificar o seu jeito de ser para agradar ao diferente, sendo que a sua genuína origem pode correr o risco de disformar-se, perder a sua verdadeira forma de ser, só porque ao mundo parece ser estranho. Argumenta-se aqui que a compreensão deste ponto de vista, está incluso em toda a gama do patriotismo constitucional. Nele, a solidariedade está contemplada tanto genuinamente em si, bem como nos

\footnotetext{
1 "Do ponto de vista moral, designa um dever decorrente da tomada de consciência das obrigações recíprocas que ligam todo homem a seus semelhantes, pois cada um depende de todos. Quando a solidariedade deixa de ser mecânica para se tornar orgânica, traduzindo-se por trocas frutuosas entre os homens ou nações, tornase fator de liberdade". (JAPIASSÚ, 2006, p. 258).
}

126 • Ágora Filosófica, Recife, v. 21, n. 1, p. 121-144, jan./abr., 2021 
múltiplos níveis a saber: justiça global ou supranacional em defesa dos direitos humanos e da paz; justiça transnacional ou regional, cuidando das questões econômicas, ambientais, fiscais e justiça de solidariedade, mediante a implantação de uma genuína legitimidade e igualdade social; justiça nacional, cuja defesa de uma radical democracia está aí contemplada. Somente assim, é que, a radical legitimidade dos espaços, se torna garantida a todos. Nesse sentido, é que, por exemplo, na União Europeia, os debates estão garantidos sobre pontos divergentes e definidos os papéis tanto para os eurocéticos, circunscritos aos populistas de direita, quanto para os comunitaristas de esquerda e ou também aos chamados publicanismos de esquerda. Enquanto, deste ponto de vista, na realidade, estão situados concomitantemente os integracionistas, tanto tecnocratas quanto democratas.

Em síntese, na filosofia do direito cosmopolita defendida por Habermas, é possível observar que está presente o problema da prática política como uma questão de primazia ontológica do ser humano. E o seu ponto fulcral reside na questão de garantir a efetivação das democracias no âmbito transnacional, sem desvalorizar os blocos regionais. Desse modo, se faz necessário entender os desafios que circunscrevem um universalismo dotado de sensibilidade para as diferenças e a inclusão. Isso, de maneira indubitável, leva necessariamente em conta que, num regime de democracia transnacional, os cidadãos se dedicam com afinco à promoção da paz, ao combate às guerras, à violência legítima em defesa dos direitos humanos.

Neste ínterim uma "política doméstica global" fundamenta-se na teoria normativa de busca do consenso, 
que se pode chamar de modelo pós-político. Para tanto, se faz necessário eliminar a radicalidade do conflito e, em face das adversidades que querem nocautear o necessário diálogo que constrói a paz, é preciso mostrar que "a coruja de minerva bateu asas muito depois do anoitecer". Ou seja, para as realidades conflituosas, não se deve haurir soluções fáceis e simplórias, é preciso ter uma cabeça giratória e olhar aguçado para no escuro do anoitecer, ter uma visão ampla e precisa do seu entorno. Em face desse desafio de fomentar uma sensibilidade que possibilite a inclusão indiscriminada do outro, é que se leva em conta a importância de organismo internacionais como a ONU, a Sociedade Interamericana de Direitos Humanos, a UNESCO e tantas outras instituições, cujas atrocidades são menores em vista de sua atuação. Neste sentido, é que se fala tanto no papel dos organismos internacionais. Eles, mesmo que de forma tímida, estão sempre atuando em prol da busca de uma legitimidade democrática. Nela está contida a defesa da vida, bem como a inclusão do outro, como utopia que é inerente à implantação de uma 'paz perpétua'.

\section{As Tensões em Níveis Locais, Regionais e Nacionais e a Filosofia do Direito de Habermas}

Ao debruçar sobre este tema, indaga-se: seria possível pensar uma constituição sem o Estado? Como por exemplo, a União Europeia teria uma Constituição, mas não necessariamente estaria restrita a um Estado. Importante recordar que do ponto de vista histórico, é que as questões culturais situadas em torno do final do Século XIII, fizeram com que surgissem a necessidade das constituições. Essas eclodem como um desdobramento do lluminismo. É uma lógica que circunscreve aquilo que se 
chama de governança mundial sem governo moderno. Neste campo, como motivações, estão muito atreladas, tanto o regime de anistia quanto as questões da violência simbólica, bem como a cultura da imagem, do direito eticamente impregnado, onde o direito que prevalece é sempre aquele ditado pelas sociedades hegemônicas. Eles é que acabaram desembocando na atual e incontrolável crise humanitária da contemporaneidade.

Neste sentido, é que, o filósofo e sociólogo alemão, retoma a memória da criação e implementação dos direitos humanos no âmbito global e interno dos Estados. Para entender este ponto é que se defende que, revisitar o texto A ideia kantiana de paz perpétua, à distância histórica de duzentos anos, possibilita um viés de reflexão interessante. Neste ponto o autor dedica de maneira especial.

Entende-se que a paz perpétua para o fomento de um Estado Cosmopolita, na filosofia do direito habermasiana, eclode como ponto de atração e de força intuitiva, como se pode observar:

Ao lado do direito do Estado e do direito das gentes, aparece o direito cosmopolita, e essa é uma invocação rica em consequência. A ordem republicana de um Estado constitucional democrático fundamentado nos direitos humanos não exige somente um enquadramento brando, em termos de direito internacional, das relações internacionais, dominadas pela guerra. Mais do que isso, o Estado jurídico no interior de um Estado deve culminar em um Estado jurídico mundial que congregue os povos e elimine as guerras. (HABERMAS, 2018, p. 281).

Nesse sentido, entende-se que a utopia da constituição de um Estado jurídico mundial que congregue

Ágora Filosófica, Recife, v. 21, n. 1, p. 121-144, jan./abr., 2021 • 129 
os povos e elimine as guerras, em se tratando de tempos de intolerância, não pode se entendido como uma quimera vazia, mas como uma norma eterna e imprescindível para toda constituição civil, cuja eliminação das guerras seja uma meta e um desafio enfrentado até o fim.

Argumenta-se que, a consequência de afastamento de toda guerra circunscrita ao direito das gentes, efetivase quando a busca pela paz perpétua kantiana faz eclodir, estiver solidificada nas bases republicanas de um Estado cosmopolita. Entende-se que é preciso levar em conta que toda essa teoria kantiana, que se pode chamar de direito racional, mesmo que pertencente à cultura de sua época, reivindica e inspira uma metacrítica aos argumentos hodiernos de uma mentalidade isolacionista e de fechamentos, que em nada contribui para a inclusão do outro.

Sabe-se que os conceitos atuais de legitimidade internacional estão bastante avançados, mas é inegável o que as experiências históricas têm mostrado: as consequências e atrocidades de um sistema de famigerada acumulação tem conduzido inúmeros seres humanos a um estado de miséria, remetendo a dignidade humana à idade das trevas. Frente a isso, há de ser consenso, de que uma solução urgente precisa ser buscada a fim de que o respeito mútuo se torne uma realidade.

Em vista da situação mundial de crise humanitária hodierna, que atinge a tudo e a todos, reivindica-se uma via alternativa, cujo universalismo kantiano do direito cosmopolita e de direitos humanos, - não obstante as suas diferenças -, precisam ser sempre preservados de um certo jurisdicismo eticamente impregnado que, muitas 
vezes, desvela-se trágico e cruel. Percebe-se que de forma irreverente, ludibriam-se e burlam-se as leis para fazerem prevalecer os privilégios das castas dominantes, mesmo que para isso seja necessário "fazer justiça com as próprias mãos" (...) [ou] "justiça a todo custo". (DEMORI, L; POUGY, V; VIEGAS, N. et al., 2019, p. 34).

Vale ressaltar que a ideia kantiana de paz perpétua aponta para a eliminação da guerra com a criação daquilo que foi 'batizado' de “Estado jurídico". A esse respeito assevera: "Não deve haver guerra, deve-se pôr um fim a desastrosa prática de guerra". (In. HABERMAS, 2018, p. 283). Não é preciso muita inteligência para pontificar que os males da guerra, por si só, já são suficientes para conclamar a todos o seu fim. A situação do tempo presente, não faltam autoridades que aclamam o recurso à guerra e tristemente com inúmeros seguidores, como se pode ver abundantemente esta mentalidade nas redes sociais que hoje agregam força inaudita.

$E$, tanto na época kantiana, quanto na contemporaneidade, é importante registrar que a defesa da paz e o combate à guerra se faz, não necessariamente, se referir diretamente às vítimas fatais, mas ao horror mesmo da violência e da devastação. Como se sabe, elas causam sobretudo a pilhagem e o empobrecimento do país.

Se faz necessário ter presente que os gastos exorbitantes da guerra provocam não só a subjugação como a perda da liberdade e a dominação estrangeira. Em se tratando de Brasil, o "teatro" triste e deprimente que se tem visto desde que foi dada a largada para o rompimento de um Estado Democrático de Direito, com o impeachment da Presidente Dilma, vem mostrando quanto gasto para manter tudo isso. Tristemente as encenações 
continuam com as mensagens da Lava Jato. Neste quesito, observa-se que o direito internacional tem mostrado a sua impotência e morosidade para agir. Isso tudo sob o argumento de respeito à soberania internacional. Ministros no banco dos réus continuam a falar como se tivesse moral para isso. Em qualquer outro país, já teria sido afastado até que as acusações se esclarecessem.

Frente ao exposto, indaga-se: até quando vai se arrastar essa situação? Os conflitos locais, regionais e nacionais se instauram e eternizam, enquanto isso, as instituições se corroem e fragilizam. Os cidadãos se digladiam e saem empobrecidos. Na medida em que as desigualdades se acentuam e as assistências de saúde, educação e segurança se esvaem. Argumenta-se que a filosofia do direito não pode lavar as mãos a todos esses descalabros. Se faz necessária uma palavra devidamente autorizada no sentido de possibilitar às pessoas uma capacidade de olhar transponível a fim de que as polarizações sejam eliminadas. Sabe-se que os conflitos fabricados são instaurados intencionalmente a fim de desviar o real debate que necessita ser feito. Entende-se que a reflexão que necessita ser feita trata-se daquela que conduz os cidadãos para a cultura do consenso e da valorização do outro, sem necessidade de criminalização do debate e nem de eliminação do oponente. Esse modo de vez proporciona sim a valorização e inclusão do outro, independentemente de sua condição, seja ela qual for: econômica, sexual, religiosa e ou política. Argumenta-se que há a urgente necessidade de conduzir os cidadãos do mundo para o caminho da legitimidade e do respeito mútuo, da democracia e da ética. Entende-se que, inevitavelmente, o fomento de rodas de conversas sobre as questões de crise humanitária da contemporaneidade 
possibilitará a esse cidadão o entendimento da necessidade constante da fuga do estado de barbárie e da guerra, e Ihe favorecerá o entendimento de que onde a cultura de que os fins justificam os meios seja aceita como normal, está o embrião de mentalidades segregacionistas e asquerosas.

Entende-se assim, que se faz necessário advertir para as consequências e os malefícios que a guerra possibilita. Ela traz o embrutecimento dos costumes. Nesse quesito, é importante mostrar que aí estão contempladas as "ações ilegais como a espionagem, a propagação das falsas notícias ou a perfídia - por exemplo, com franco-atiradores ou assassinos de tocaia" (HABERMAS, 2018, p. 283). Se observamos as espionagens da atualidade, desde as questões referentes aos impasses da Lava Jato, por exemplo, perpassando pelas falsas notícias do período eleitoral, até os assassinatos ou execuções políticas, como é o caso da vereadora Marielle Franco, no município do Rio de Janeiro, ratifica-se a necessidade urgente de um "Estado Jurídico" instalado de modo que, justamente por respeitar as soberanias nacionais, quando se trata de abuso e maus tratos humanos, os poderes transnacionais sejam capazes de agir, a fim de que o respeito para com o outro seja garantido.

Numa busca pela política de consenso e de prevenção da criminalização dos reais debates que precisam ser feitos, entende-se que aí se torna possível que, a eliminação do oponente, seja combatida, a fim de que a paz se instale e o combate à guerra seja constante, como meio legítimo de solução de conflitos. A esse respeito, argumenta-se que quando se tem uma sociedade que valoriza a cultura do respeito mútuo e de 
uma educação para o coletivo, implanta-se o término de qualquer vocação para a guerra e a busca constante para o desejado desafio de implantação de um Estado e cultura da paz.

Nesse sentido é que o autor pondera que: "da mesma maneira que um determinado contrato de paz acaba com o mal de uma única guerra, assim uma liga de paz deve agora acabar para sempre com todas as guerras, e afastar o mal da guerra como tal. Esse é o significado da paz perpétua. A paz está tão limitada como a própria guerra". (HABERMAS, 2018, p. 284). Sabe-se que Kant não pensava em guerras mundiais, mas em guerras entre gabinetes e Estados, por exemplo. Mas na contemporaneidade, as guerras estão com configurações diversas, desde as tecnológicas até as ideológicas, sem falar do terror das bombas e de expulsões do outro, motivadas ideologicamente. Mesmo que para tanto, apenas se quer é respeitar o outro pelo simples fato de ele existir.

Nesse sentido vale lembrar as questões de perseguições e preconceitos para com as minorias e que usam por exemplo, o recurso ao maniqueísmo com a "diabolização" da ideologia de gênero, (só para citar um exemplo), a fim de disseminar com a misoginia, as discórdias e preconceito; quando na verdade, o grande desafio que se espera, por parte de todos, é exatamente a inclusão do outro, independentemente de sua condição de sexo, raça e ou etnia. Nesse sentido, se faz necessário recordar que: "Sob as premissas da guerra limitada, o âmbito normativo do direito internacional se estende à condução da guerra e à regulamentação da paz". (HABERMAS, 2018, p. 285).

Em outros termos, o direito à guerra, anteposto ao 
direito na guerra, bem como depois dela, não é um direito, mas apenas faz eclodir a liberdade de arbítrio própria dos sujeitos internacionais no estado de natureza e nas relações mútuas do estado sem leis. Sendo assim, as únicas leis punitivas a intervirem nos estados sem leis, referem-se estritamente às condutas na guerra e que devem, necessariamente, serem aplicadas pelos próprios tribunais dos países sem leis. Isto, no entanto, mostra que, quando se tem um direito eticamente impregnado e um poder jurídico cooptado pelas forças políticas hegemônicas, dificilmente tais leis serão aplicadas e, reina então a famigerada violação do estado de direito. Este que é tão necessário para a garantia da inclusão do outro e respeito de todos. Nesse sentido, argumenta o filósofo alemão, que "somente a ampliação do que é a guerra, (...) e a respectiva ampliação do conceito de paz suscita, a ideia de que a própria guerra (...), é um crime que merece ser prescrito". (HABERMAS, 2018, p. 285).

Vale ressaltar que por mais importante que seja o anseio de paz perpétua, a partir da visão habermasiana, ela é apenas um sintoma do Estado cosmopolita. Há aqui uma necessidade de diferenciar o que é realmente o direito cosmopolita e o direito das gentes, a saber:

Enquanto o direito das gentes, como todo direito no estado de natureza, apenas vale de modo peremptório, o direito cosmopolita, tal como o direito sancionado pelo Estado, acabaria definitivamente com o estado de natureza. Por isso na passagem do Estado cosmopolita, Kant recorre continuamente à analogia daquela primeira saída do estado de natureza que, pela constituição contratualista de um determinado Estado, torna possível aos cidadãos de um país uma vida de liberdade assegurada por meios legais. Da mesma maneira que se deu o término do estado de

Ágora Filosófica, Recife, v. 21, n. 1, p. 121-144, jan./abr., 2021 • 135 
natureza entre os indivíduos isolados, assim também deve ser dado um fim ao estado de natureza entre Estados belicistas. (HABERMAS, 2018, p. 285).

Defende-se aqui a necessidade de resolver os conflitos por meio de um processo e não mediante a guerra. Entende-se que isso é dado por meio de uma autovinculação moral dos governos, de modo que a coerção jurídica não tem lugar na maneira kantiana de conceber a política. Nesse sentido, a razão torna-se o único caminho plausível na defesa do direito das gentes que deve sobrepor a interesses instáveis sem a necessidade de qualquer poder legislativo e ou coercitivo superior. Entende-se que o federalismo livre legitima a mútua compreensão de que, mesmo aquele estado que seja soberano economicamente, deve lhe ser inerente na convivência pacífica, em detrimento dos malefícios da guerra.

Essa utopia kantiana é corrigida por ele próprio ao tomar consciência de que a boa formação moral dos seus membros não seria suficiente para garantir o bem de todos. O grande desafio nessa perspectiva kantiana seria então o fomento de uma federação de Estados livres, comprometidos com uma política de poder comum. "Kant viu na crescente interdependência das sociedades promovida pela troca de notícias, pessoas e mercadorias, mas principalmente na expansão do comércio, uma tendência que favorecia a união pacífica dos povos". (HABERMAS, 2018, p. 293).

Contudo, é sabido que o mero apelo de um direito internacional simplesmente fracassou, mediante o fato da trágica eclosão das guerras totais desencadeadas no 
século XX. Argumenta-se de que as fortes forças propulsoras que promovem as guerras só serão eliminadas mediante intervenções de comunidades dos povos organizados, de modo muito mais eficiente do que o discernimento de governos soberanos. Pois entende-se que, a liberdade de executar ações plenas atribuídas aos atores coletivos, possibilita maiores chances de alterar comportamentos incivilizados.

Em síntese, a partir da filosofia do direito na perspectiva habermasiana, argumenta-se que a propensão ao fundamentalismo dos direitos humanos só será evitada na medida em que o estado de natureza entre os Estados for transformado em um Estado jurídico, circunscrito àquilo que se entende em termos de direitos cosmopolita.

\section{Ocidente Dividido e os Entraves de uma Cultura da Polarização}

Em face dos grandes desafios da contemporaneidade, indaga-se: existe chance para o fomento de um direito internacional? Se se pensar em termos de espírito da lei, inevitavelmente, e do ponto de vista racional, seria plausível entender que, em face de uma busca coletiva pela paz, sempre é preciso lutar para a promoção da igualdade soberana, bem como a busca indiscriminada da liberdade de todos, em conformidade com as leis.

Sabe-se que os interesses que regem o lucro e o afã de poder travam a constituição supranacional de uma legitimação democrática, que possibilite a vida plena para todos os cidadãos do mundo. Contudo, é mister acreditar e lutar pela busca de convergência e consensos, a fim de que as divisões possam dar lugar à convivência 
democrática e pacífica. A esse respeito, argumenta-se que:

À luz da ideia kantiana e partindo das estruturas hoje existentes, podemos pensar uma constituição política da sociedade mundial descentralizada como um sistema de múltiplos níveis em que por boas razões, falta o caráter estatal como um todo. Segundo essa representação, no plano supranacional, uma organização mundial reformada adequadamente conseguiria desempenhar de forma efetiva e não seletiva as funções vitais, mas especificadas precisamente, da manutenção da paz e da política de direitos humanos sem precisar assumir a forma estatal de uma república mundial. Num plano transnacional intermediário, no âmbito de conferências e sistemas de negociação permanentes, os grandes atores com capacidade de atuação global trabalhariam com os problemas difíceis de uma política interna mundial não só coordenadora, mas também configuradora, com especial atenção para os problemas da economia mundial e da ecologia. (HABERMAS, 2016, p.189).

Entende-se que, a simples carência de estados suficientemente fortes para colocar em prática esse ideal, impossibilita a sua efetivação, uma vez que sempre o risco de dominação e da ganância podem prevalecer. No cenário atual, com exceção dos Estados Unidos e das evidências atuais do poderio tecnológico chinês ${ }^{2}$, os

2 Ao se referir ao caso brasileiro, Miguel de Almeida (In Folha de São Paulo de 02/06/2019/tendência e debates) provoca uma séria reflexão. A esse respeito, argumenta que: "À falta de imaginação da esquerda, transformada num cartório das corporações sindicais, se juntou o acanhamento da centro-direita, hoje uníssona sob a bandeira da reforma da Previdência. A agenda se concentra na questão das aposentadorias, embora o mundo desenvolvido discuta o 5G, a guerra tecnológica com a Hauwei e o fim do emprego. O cenário pós-Segunda 138 • Ágora Filosófica, Recife, v. 21, n. 1, p. 121-144, jan./abr., 2021 
demais países necessitam somar forças entre si, como é o caso dos blocos como União Europeia, Mercosul, Blocos Asiáticos a fim de serem capazes de agir na política externa. Desse modo, são capazes de impedir que as guerras se tornem meios de solução dos conflitos.

Sabe-se que desse poder conjunto emana uma força considerável para impedir a guerra, garantir minimamente a paz e agir em defesa dos direitos humanos. Neste caso específico, entende-se que entra a Carta das Nações Unidas no plano supranacional. Assim, as negociações concernentes aos problemas de uma política interna mundial, se tornam realidade ao propugnar uma espécie de acordo entre as superpotências, que por sua vez, tornam-se "domesticadas". Com este modo de pensar, Habermas possibilita o entendimento de que, de forma figurada, é possível a existência de uma "república mundial" ou de um "Estado dos povos". E é nesse sentido que se refere ao conceito de Estado cosmopolita possibilitado em escala global.

Por um lado, este modo de argumentar, fomenta, pois, a compreensão mais efetiva da utopia de transição de um modelo de república mundial, utilizado para ilustrar a passagem do direito internacional para o direito cosmopolita. Contudo, se faz necessário entender, que nesse pensamento, se destacam três elementos essenciais: o caráter estatal, a solidariedade cidadã e a constituição. Eles se separam quando se está além do Estado nacional. Argumenta-se que a leitura habermasiana aponta hoje para a necessidade de uma

Guerra Mundial - carteira assinada, única profissão a vida inteira, missa aos domingos - pertence a quem cultiva um reacionarismo cevado no dízimo".

Ágora Filosófica, Recife, v. 21, n. 1, p. 121-144, jan./abr., $2021 \cdot 139$ 
retomada da proposta kantiana de construção do sonho da paz perpétua. Ele assevera que a desafiadora realidade de uma sociedade culturalmente fraturada e estratificada do presente, com um alto nível deterioração humana e ambiental, necessita urgentemente de uma constituição política que favoreça e garanta a paz.

É público e notório que as sociedades se encontram desgastadas, principalmente pela ânsia de acumulação e dominação que geram divisões e rixas, cuja polarização em nada contribui. Em face disse, conseguir dar um passo sincronizado na direção de uma ética e cultura democráticas, talhadas pela solidariedade, torna-se um enorme desafio. Em face de tamanhos desafios e ameaças à vida digna, a possibilidade de consolidar uma constituição supranacional e, concomitante, a legitimação democrática reivindica grandes esforços, a fim de se criar uma cultura de busca do consenso e de tendências convergentes. Para Immanuel Kant, o fomento de um Estado cosmopolita ganha forma efetiva na constituição de uma república mundial.

Por outro lado, argumenta-se que a estrutura cosmopolita do mundo hodierno não comporta um modelo de estado cosmopolita, por causa da configuração profundamente pluralista do mundo. A esse respeito, há quem pensa muito diferente e se coloca absolutamente cética em relação à possibilidade de efetivação de um estado cosmopolita diante de uma cultura multipolar. Sobre isso, é possível ver que:

Os defensores de um novo cosmopolitismo partilham a crença liberal na superioridade da democracia liberal - cujas falhas já examinei - e almejam expandir os princípios democráticos liberais para a esfera das relações internacionais. Uma de suas principais propostas é reformar as 
Nações Unidas e aumentar o poder das instituições judiciais internacionais a fim de assegurar o primado da lei sobre a força e o exercício do poder. (MOUFFE, 2015, p. 90).

A distinção dessa visão entre uma vertente mais democrática de uma mais liberal, se faz notar mediante as diferentes posturas de parcelas de cidadãos entre eles evidenciados. Os partidários da versão neoliberal defendem a promoção do livre comércio e da democracia liberal. A exaltação de uma ala protagonista da globalização, exaltadora das vantagens e benesses do capitalismo enfatiza-o como um bem para todo o cosmo. Eles argumentam que, sob a batuta dos organismos internacionais, como o FMI, OMC, OCDE, atrelados aos interesses do capital financeiro mundial, especialmente os EUA, será possível implementar uma ordem mundial justa.

Nesse sentido, a utopia capitalista é "freada" graças ao entendimento de que o Estado-nação goza de uma soberania que, mesmo em face da globalização, essas balizas de respeito das esferas nacionais ainda sobrevivem. Mesmo sendo evidente para qualquer pessoa minimamente atualizada acerca da geopolítica mundial, de que na hegemonia neoliberal assimila por força de seu viés ideológico, qualquer possibilidade de contra argumentação e ou metanarrativa que desbancam os seus dissimulados interesses, elucida que na política, ela não abre vez a qualquer espaço de decisão. Em face dessa crítica, argumenta-se que, qualquer tipo de tentativa política sob a "liderança benigna" dos Estados Unidos, "tudo está subordinado à esfera econômica e à soberania do mercado". (MOUFFE, 2015, p. 91). Já a vertente democrática, acaba se tornando mais interessante e 
maleável uma vez que não considera a política global como um processo meramente marcado pela economia autorregulada. Ela abre atribuições maiores para a esfera política do que a vertente neoliberal. Sendo assim, ela facilita as relações entre sociedade civil e política. Nesse ponto, considera que a sociedade civil é um lugar privilegiado da realização democrática da vida. Nesse ínterim, o campo político e de exercício da cidadania possibilita uma vivência democrática anticoercitiva e de cultura cívica, cuja associação, participação e mobilização em face das tomadas de decisões justas se fazem prevalecer.

Nesse sentido é preciso recordar que "os potenciais da crise econômica, dominada pela política, se deslocariam para imperativos contraditórios no interior de um aparelho estatal sobrecarregado e para a 'contradições do capitalismo, manifestando-se na forma de uma crise de legitimação. (HABERMAS, 2014, p. 183). Na atualidade, a leitura de Habermas possibilita entender que é gritante não somente com uma crise de legitimação e uma crise econômica palpável, mas também uma crise de valores que agrava cada vez mais a utopia de resolver os problemas. Isso aponta que, cada vez mais, fica grave a situação de um ocidente dividido, cujos entraves são a acentuação de uma cultura de polarizações sem precedentes.

\section{Considerações Finais}

A presente abordagem procurou, de forma longitudinal e simples, abordar as consequências de um conteúdo universalista para os princípios republicanos numa realidade de uma cultura pluralista. Sem negligenciar qualquer outro dado, vale recordar aqui que,

142 • Ágora Filosófica, Recife, v. 21, n. 1, p. 121-144, jan./abr., 2021 
as taxas de inflação crescentes nos entornos do ano 1970, provocaram um endividamento crescente nos orçamentos públicos e privados, dando lugar ao ponto em que se encontra a humanidade. Atrelada a esse dado, nota-se a crescente desigualdade na distribuição das riquezas se torna acentuada como efeito dominó. A desigualdade social ganha corpo e desencadeia o que ficou conhecido como Estado dos impostos que, posteriormente tornou-se Estados das dívidas, de modo que a subsistência estatal passa a valer-se não apenas das contribuições cidadãs, mas da confiança dos credores para sobreviver. A essa altura vale registrar que, a origem da interdependência e da soberania de um povo sobre outro, tem a sua gênese nesse processo de endividamento do Estado de modo que, "a transformação do Estado dos impostos no Estado das dívidas forma hoje o pano de fundo de um círculo vicioso que consiste no Estado resgatando bancos arruinados, e depois esses mesmos bancos, por seu turno, empurrando os Estados à ruína - com a consequência de que o regime financeiro dominante coloca suas populações sob tutela". (HABERMAS, 2014, p. 185).

Em face de uma política da crise e de um dado real das fragilidades institucionais, de Estados em alerta, reivindica-se dos cidadãos e dos estados uma capacidade sem igual na consolidação de uma cultura da flexibilidade em face da concorrência. Em se tratando de União Europeia, por exemplo, assevera Habermas, que há duas alternativas sob a mesa: ou uma involução defensiva do euro, ou uma reestruturação ofensiva da comunidade monetária, formando uma democracia supranacional. Nesse sentido, entende-se que a democracia supranacional fomenta uma plataforma institucional capaz de desbancar a tendência neoliberal, caso forme 
uma política de coalizão em prol da consolidação da paz. O debate fica aberto, e mostra como os caminhos são tortuosos e as situações são de encruzilhadas.

\section{Referências}

DEMORI, L; POUGY, V; VIEGAS, N. et al. Justiça a todo custo. São Paulo: Revista Veja. Edição 2642. Ano 52, n. 28. [pp 34-43].

HABERMAS, Jürgen. $\mathbf{N a}$ esteira da tecnocracia: pequenos escritos políticos. Trad. Luiz Repa. São Paulo: Unesp, 2014.

HABERMAS, Jürgen. A inclusão do outro: estudos de teoria política. Trad. Denílson Luís Werle. São Paulo: Unesp, 2018.

HABERMAS, Jürgen. 0 Ocidente dividido: pequenos escritos políticos. Trad. Bianca Tavolari. 1.ed. São Paulo: Unesp, 2016.

MOUFFE, Chantal. Sobre o político. Trad. Fernando Santos. São Paulo: Martins Fontes, 2015.

JAPIASSÚ, Hilton. Dicionário básico de Filosofia. 4.ed. atual. Rio de Janeiro: Zahar, 2006.

MERKEL, Ângela. Discurso em Harvard. In. Folha de São Paulo. São Paulo. A2. Ano 99, de 02/06/2019.

José Aguiar Nobre

Pós-doutorado em Filosofia e Educação. Doutor em Teologia. Mestre em Educação. Doutorando em Filosofia. Docente do Departamento de Teologia da PUC-SP.

E-mail: nobre.jose@gmail.com

Submetido: $19 / 05 / 2020$

Aprovado: 15/08/2020

144 • Ágora Filosófica, Recife, v. 21, n. 1, p. 121-144, jan./abr., 2021 